\title{
Outcome After Selective Laser Trabeculoplasty for Glaucoma Treatment in a Thai Population
}

This article was published in the following Dove Press journal:

Clinical Ophthalmology

\section{Panrapee Funarunart (ID Isaraporn Treesit}

Department of Ophthalmology, Phramongkutklao Hospital, Phramongkutklao College of Medicine, Bangkok, 10400, Thailand
Correspondence: Isaraporn Treesit Department of Ophthalmology, Phramongkutklao Hospital,

Phramongkutklao College of Medicine, Bangkok, 10400, Thailand

Tel +66896651949

Fax +662 3549309

Email isaraporn.treesit@gmail.com
Purpose: The study aimed to evaluate the efficacy and predictive factors of success after selective laser trabeculoplasty (SLT) for treating various types of open-angle glaucoma in a Thai population.

Design: The study employed a retrospective cohort design.

Materials and Methods: The study retrospectively recruited Thai subjects diagnosed with open-angle glaucoma receiving first time selective laser trabeculoplasty. Primary open-angle glaucoma (POAG), ocular hypertension (OHT) and other types of open-angle glaucoma were included. Reduced intraocular pressure (IOP) of $20 \%$ or decreased number of antiglaucoma drugs usage after SLT was defined as success. Various parameters were analyzed for association with SLT success.

Results: Ninety-six eyes were recruited in the study. Mean pre- and postSLT IOP were 19.31 \pm 3.59 and $15.04 \pm 3.13 \mathrm{mmHg}$, respectively. IOP decreased significantly in all follow-up visits $(\mathrm{p}<0.001)$. Overall, 59.4\% met the treatment endpoint. More than $10 \%$ postSLT IOP elevation at 1 hour was the only covariate positively associated with SLT success in both univariate (odds ratio $(\mathrm{OR})=1.042, \mathrm{p}=0.037)$ and multivariate analyses $(\mathrm{OR}=1.040$, $\mathrm{p}=0.046$ ). Underlying hypertension and preSLT IOP were negatively associated with SLT success in both univariate $(\mathrm{OR}=0.970, \mathrm{p}=0.026, \mathrm{OR}=0.955, \mathrm{p}<0.001)$ and multivariate analysis $(\mathrm{OR}=0.970, \mathrm{p}=0.026, \mathrm{OR}=0.991, \mathrm{p}<0.001)$.

Conclusion: IOP significantly decreased as well as the number of antiglaucoma drugs needed after SLT. More than $10 \%$ postSLT IOP elevation at 1 hour was a positive predictor whereas systemic hypertension and preSLT IOP were negative predictors of SLT success.

Keywords: selective laser trabeculoplasty, outcome, success, factors, Thai

\section{Introduction}

Glaucoma is a major public health problem affecting people of all ethnicities worldwide. Its effect on visual function leads to disability and impaired quality of life. Reducing intraocular pressure (IOP) is the most powerful treatment for all types of glaucoma. Selective laser trabeculoplasty (SLT) is a laser treatment of glaucoma widely used for this purpose. SLT can be used as an adjunctive or even a primary treatment in primary open-angle glaucoma (POAG). ${ }^{1}$ SLT is a safer procedure, less invasive and causes less serious complications compared with glaucoma surgery. The procedure is also more convenient for patients as it can be performed in clinics, generally causing minimal discomfort and requiring less recovery time. Its popularity increases when considering patients' compliance and side effects of antiglaucoma medication which represents a major concern in treating chronic glaucoma. ${ }^{2}$ 
Efficacy of SLT in POAG varied from study to study, and many studies have shown promising results. SLT reduced IOP by $6.5 \mathrm{mmHg}$ at 3 years of follow-up compared with argon laser trabeculoplasty. ${ }^{3}$ A successful treatment is mostly defined as $20 \%$ IOP reduction. At 1 year follow-up, the success rates of SLT in early OAG and advanced OAG were $63 \%$ and $59.1 \%$, respectively. ${ }^{4}$ Another study showed the success rates of SLT at 6-month follow-up in POAG and pseudoexfoliation glaucoma (PXG) of $75 \%$ and $94.1 \%$, respectively. ${ }^{5}$ On the contrary, Song et al reported less favorable results. ${ }^{6}$ SLT is not only applied in POAG and pigmentary glaucoma, but also in other types of open-angle glaucoma with favorable results such as $22 \%$ success rate at 1 year in normal tension glaucoma (NTG) ${ }^{7,8}$ and $46.7 \%$ at 1 year in steroidinduced glaucoma. ${ }^{9}$ The variability of SLT success rate suggests the possibility that some factors alter the efficacy of SLT.

One factor reported to be strongly associated with success was higher preSLT IOP. ${ }^{6,10,11}$ Some studies have found other factors exhibiting a positive effect on success rate, such as type of glaucoma, ${ }^{12}$ no prior use of antiglaucoma medication, ${ }^{13,14}$ use of carbonic anhydrase inhibitors (CAIs) before SLT, eyes with thinner retinal nerve fiber layer (RNFL) and eyes that had lower IOP at 1 day after SLT. ${ }^{15}$ This information is important because it helps ophthalmologists and patients for planning their treatment regime.

Although SLT is a safer treatment method, the chance of potential complications remains. ${ }^{16}$ In addition, the effectiveness of reducing IOP decreases over time, with a failure rate of $50 \% 2$ years after treatment. ${ }^{3}$ SLT can be repeated causing reduced IOP lasting up to 2 years of follow-up. ${ }^{17}$

All information about efficacy, duration of action and predictive factors associated with successful treatment are still limited in Southeast Asian populations. In this study, we planned to evaluate the efficacy and predictive factors of success after SLT for treating various types of openangle glaucoma in a Thai population.

\section{Materials and Methods}

The study employed a retrospective cohort design. The documents of Thai race subjects receiving a diagnosis of unilateral or bilateral open-angle glaucoma undergoing first time SLT at the Ophthalmology Clinic of Phramongkutklao Hospital, Bangkok, Thailand, a tertiary medical college hospital from January 2017 to
December 2018 were retrospectively reviewed. Primary open-angle glaucoma (POAG), normal tension glaucoma (NTG), ocular hypertension (OHT), pseudoexfoliation glaucoma (PXG), juvenile open-angle glaucoma (JOAG) and other secondary open-angle glaucoma such as steroidinduced glaucoma or angle recession which was not contraindicated for SLT were all included. Subjects were excluded if they had peripheral anterior synechiae before SLT treatment, or follow-up time less than 6 months, or receiving new medication or modified current medication regime which might affect IOP such as any form of steroid, or undergoing ocular surgery other than glaucoma intervention during first 6 months, or missing study parameters.

All subjects underwent a single session of SLT performed by one of four glaucoma specialists working at the clinic. All treated eyes were installed with $2 \%$ Pilocarpine and $0.5 \%$ Tetracaine hydrochloride at 30 minutes and 5 minutes prior to the laser treatment, respectively. SLT was performed with a frequency-doubled Q-switched Nd-YAG laser emitting at $532 \mathrm{~nm}$ with pulse duration of 3 nanoseconds and a spot size of 400 microns focusing on trabecular meshwork (Optimis Fusion, Quantel Medical, Cournon d'Auvergne, France). Initial energy was $0.7 \mathrm{~mJ}$ which was titrated until air bubble was visible. Extension of the laser area and post-operative prescription were depended on surgeon's preference. IOP measurement and slit lamp examination were performed in all treated eyes one hour after SLT. Subjects were advised to continue their glaucoma medication regime unless whom had any side effect from their medication. Follow-up visits included 1 week (optional), 1, 3, 6, 12, 18 and 24 months after SLT treatment.

The following parameters of the treatment date were recorded: age, sex, underlying systemic and ocular disease, type of eyedrop other than antiglaucoma drug and artificial tear, type of glaucoma, preSLT number of antiglaucoma drugs, preSLT type of antiglaucoma drug, duration of antiglaucoma drug usage before SLT, best corrected visual acuity (BCVA), preSLT IOP, gonioscopic grading, lens status, cup to disc ratio (C:D), visual field mean deviation (VFMD), indication of SLT treatment, laser power, total laser energy, location of SLT, IOP and slit lamp examination findings at an hour after SLT, complication and postSLT medication. At the follow-up visits, these parameters were recorded: VA, number and type of antiglaucoma drugs, IOP, gonioscopic grading, lens status, C:D ratio, complication and type of additional intervention or 
intraocular surgery. All IOP readings were measured using Goldmann applanation tonometry. PreSLT IOP was the mean IOP measured at the last 2 visits before laser treatment. The records were terminated when subjects received new medication or modified current medication regime which might affect IOP such as any form of steroid, or undergoing any intervention or intraocular surgery, or missing study parameters.

This study adhered to the tenets of the Declaration of Helsinki and its later amendments or comparable ethics standards. It was approved by the Institutional Review Board (IRB), Royal Thai Army Medical Department. As it was a retrospective chart review which involved minimal risk. Therefore, a request for waiver of consent was submitted to the IRB and it met their criteria. To ensure that patient confidentiality was maintained, all data retrieval was performed by the principal investigator using a password-secured computer. Each patient's record form was assigned a subject ID code and did not contain any identifying information. All identifiable data were encrypted and only the principal investigator could access it. Data will not be used for any other purposes than those described in the study protocol. The authors declared they had no financial interests.

\section{Statistical Analysis}

A reduced IOP of $20 \%$ or decreased number of antiglaucoma drugs needed after SLT was defined as a successful treatment. Comparison within study population was calculated using paired $t$-test. Continuous variables were reported as mean $\pm \mathrm{SD}$ (range) while categorical variables were reported as number (\%). In all, 20 covariates were determined using univariate analysis to identify whether they were associated with SLT success. Multivariate analysis was then conducted by excluding covariates which had collinearity with others. Associations were reported as odds ratio (OR) and a p-value of $<0.05$ was defined as statistically significant.

\section{Results}

Ninety-six eyes of Thai subjects were recruited in the study, involving 33 subjects who received SLT bilaterally. Mean age was $65.81 \pm 12.91$ and $54.2 \%$ were male. Eyes were POAG (76\%), OHT (8.3\%), JOAG (5.2\%), NTG (3.1\%), PXG (3.1\%) and other secondary open-angle glaucoma (4.3\%). Most eyes $(65.5 \%)$ had moderate to advanced stage of glaucoma for which mean VFMD was $-9.35 \pm 8.14$. The majority of eyes were treated with indication of uncontrolled IOP (79.2\%). Demographic data are shown in Table 1.

Mean Pre- and postSLT IOP were $19.31 \pm 3.59$ and $15.04 \pm 3.13 \mathrm{mmHg}$, respectively. IOP was decreased significantly in all follow-up visits ( $\mathrm{p}<0.001)$. Overall, $59.4 \%$ met the definition of successful treatment at 3 months for which $33.3 \%$ of treated eyes had at least $20 \%$ IOP reduction and 30.2\% needed fewer antiglaucoma drugs (Table 2 ). The number of antiglaucoma drugs needed decreased from $2.74 \pm 1.09$ preSLT to $2.48 \pm 1.25$ and $2.16 \pm 1.31$ at 6 and 24 months postSLT, respectively $(\mathrm{p}<0.001)$. For the overall follow-up period, IOP could be controlled in $35.4 \%$ of eyes, with fewer antiglaucoma drugs compared with before SLT. At 3-month follow-up, IOP was unchanged or decreased less than $10 \%$ in $16.7 \%$ of eyes. Those eyes needed additional medication or further glaucoma surgery. In all, $3.4 \%, 8.0 \%$ and $4.8 \%$ of treated eyes needed additional intervention at 12,18 and 24 months, respectively. Four eyes which experienced a successful response to the first SLT received repeated treatment, favorable IOP reduction was still observed in all those eyes. The number of antiglaucoma drugs needed at each follow-up visit is shown in Figure 1.

In univariate analysis of covariates affecting SLT success, positive associations were found between treatment endpoint and preSLT beta-blocker used [odds ratio $(\mathrm{OR})=$ $1.120, \mathrm{p}=0.030$ ], laser location $(\mathrm{OR}=1.105, \mathrm{p}=0.040)$ and more than $10 \%$ postSLT IOP elevation at 1 hour (OR $=1.042, \mathrm{p}=0.037)$. On the contrary, negative associations were observed between SLT success and underlying systemic hypertension $(\mathrm{OR}=0.970, \mathrm{p}=0.026)$, preSLT IOP $(\mathrm{OR}=0.955, \mathrm{p}<0.001), \mathrm{NTG}$ diagnosis $(\mathrm{OR}=0.731, \mathrm{p}=$ $0.037)$, preSLT prostaglandin analogue used $(\mathrm{OR}=0.960$, $\mathrm{p}=0.035)$ and postSLT NSAIDs used $(\mathrm{OR}=0.85, \mathrm{p}=$ $0.001)$.

In multivariate analysis, BCVA, preSLT number of antiglaucoma drugs and laser power were excluded from the analysis. JOAG diagnosis $(\mathrm{OR}=1.167, \mathrm{p}=0.007)$, PreSLT topical CAIs used $(\mathrm{OR}=1.048, \mathrm{p}=0.006)$ and more than $10 \%$ postSLT IOP elevation at 1 hour $(\mathrm{OR}=$ $1.040, \mathrm{p}=0.046$ ) were positively associated with SLT success. On the other hand, underlying hypertension (OR $=0.970, \mathrm{p}=0.026)$, preSLT IOP $(\mathrm{OR}=0.991, \mathrm{p}<0.001)$ and preSLT alpha-2 agonist used $(\mathrm{OR}=0.972, \mathrm{p}=0.044)$ were negatively associated with SLT success. More than $10 \%$ postSLT IOP elevation at 1 hour was the only covariate positively associated with SLT success using both univariate and multivariate analysis. In contrast, 
Table I Demographic Data

\begin{tabular}{|c|c|}
\hline Age (year) & $65.81 \pm|2.9|(30-88)$ \\
\hline \multicolumn{2}{|l|}{ Sex } \\
\hline Male & $52(54.2)$ \\
\hline Female & $44(45.8)$ \\
\hline \multicolumn{2}{|l|}{ Underlying disease } \\
\hline Diabetes mellitus & $24(25.0)$ \\
\hline Hypertension & $45(46.9)$ \\
\hline \multicolumn{2}{|l|}{ Other ocular diseases } \\
\hline No & $81(84.4)$ \\
\hline Severe dry eye & $7(7.3)$ \\
\hline Others & $8(8.3)$ \\
\hline Follow-up time (month) & $18.09 \pm 6.33(6-24)$ \\
\hline Best corrected visual acuity (logMAR) & $0.28 \pm 0.3(0.0-1.6)$ \\
\hline IOP pre-SLT (mmHg) & $19.31 \pm 3.59(10-30)$ \\
\hline Cup to disc ratio & $0.72 \pm 0.17(0.3-0.9)$ \\
\hline Visual field mean deviation $(\mathrm{dB})$ & $\begin{array}{c}-9.35 \pm 8.14 \\
(-29.33-1.58)\end{array}$ \\
\hline \multicolumn{2}{|l|}{ Diagnosis } \\
\hline OHT & $8(8.3)$ \\
\hline POAG & $73(76.0)$ \\
\hline NTG & $3(3.1)$ \\
\hline Steroid induced & $2(2.1)$ \\
\hline PXG & $3(3.1)$ \\
\hline JOAG & $5(5.2)$ \\
\hline Angle recession & $2(2.1)$ \\
\hline $\begin{array}{l}\text { Duration of anti-glaucoma drug used } \\
\text { (year) }\end{array}$ & $5.39 \pm 3.5(0-20)$ \\
\hline Number of anti-glaucoma medication & $2.74 \pm 1.09(0-5)$ \\
\hline \multicolumn{2}{|l|}{ Anti-glaucoma medication } \\
\hline Beta-blockers & $76(79.2)$ \\
\hline Alpha2 agonists & $52(54.2)$ \\
\hline Prostaglandin analogues & $84(87.5)$ \\
\hline Topical CAls & $50(52.1)$ \\
\hline \multicolumn{2}{|l|}{ Lens status } \\
\hline Phakic & $52(54.2)$ \\
\hline Artificial foldable acrylic IOL & $44(45.8)$ \\
\hline \multicolumn{2}{|l|}{ Indication of SLT } \\
\hline Primary treatment & $2(2.1)$ \\
\hline Uncontrolled IOP & $76(79.2)$ \\
\hline Poor compliance & $5(5.2)$ \\
\hline Side effect from medication & $13(13.5)$ \\
\hline \multicolumn{2}{|l|}{ Laser location } \\
\hline 180 degrees & $23(24.0)$ \\
\hline 360 degrees & $73(76.0)$ \\
\hline
\end{tabular}

(Continued)
Table I (Continued).

\begin{tabular}{|l|c|}
\hline Laser power $(\mathrm{mJ})$ & $0.73 \pm 0.1$ I $(0.5-1.0)$ \\
\hline Total laser energy $(\mathrm{mJ})$ & $56.83 \pm 19.77(10.2-100)$ \\
\hline Complication & $73(76.1)$ \\
None & $22(22.9)$ \\
IOP spike $>10 \%$ & 0 \\
Iritis & 0 \\
Hyphema & 0 \\
Macular edema & 0 \\
Foveal burn & 0 \\
Corneal haze & $1(1.0)$ \\
Hypotony & \\
\hline Post laser medication & $65(67.7)$ \\
No & $4(4.2)$ \\
Steroid & $27(28.1)$ \\
NSAIDs & \\
\hline
\end{tabular}

Note: Continuous variables were reported as mean \pm SD (range) while categorical variables were reported as number (\%).

Abbreviations: SLT, selective laser trabeculoplasty; IOP, intraocular pressure; $\mathrm{OHT}$, ocular hypertension; POAG, primary open-angle glaucoma; NTG, normal tension glaucoma; PXG, pseudoexfoliation glaucoma; JOAG, juvenile open-angle glaucoma; CAls, carbonic anhydrase inhibitors; NSAIDs, non-steroidal antiinflammatory drugs; IOL, intraocular lens; SD, standard deviation.

underlying systemic hypertension and preSLT IOP were negatively associated with SLT success using both univariate and multivariate analysis (Table 3 ).

\section{Discussion}

In this study, IOP decreased significantly in all follow-up visits as well as the number of antiglaucoma drugs needed $(p<0.001)$. Overall, $59.4 \%$ met the definition of successful treatment at 3 months which was comparable with some studies $^{15,25}$ but lower than others. ${ }^{3,4}$ In our study, we

Table 2 Intraocular Pressure and Percentage of Intraocular Pressure Reduction at Each Follow-Up Visit

\begin{tabular}{|l|c|c|c|}
\hline & IOP & $\begin{array}{c}\text { Percentage of IOP } \\
\text { Reduction }\end{array}$ & p-value \\
\cline { 2 - 3 } & Mean \pm SD & Mean \pm SD & \\
\hline Baseline & $19.31 \pm 3.59$ & & \\
I-month & $15.14 \pm 2.93$ & $30.68 \pm 27.24$ & $<0.00 I^{*}$ \\
3-month & $14.78 \pm 3.09$ & $34.29 \pm 28.26$ & $<0.00 I^{*}$ \\
6-month & $15.31 \pm 3.33$ & $30.04 \pm 27.24$ & $<0.00 I^{*}$ \\
I2-month & $14.98 \pm 2.62$ & $30.00 \pm 27.62$ & $<0.00 I^{*}$ \\
I8-month & $15.20 \pm 3.28$ & $31.27 \pm 29.30$ & $<0.00 I^{*}$ \\
24-month & $14.79 \pm 3.67$ & $32.78 \pm 31.53$ & $<0.00 I^{*}$ \\
\hline
\end{tabular}

Notes: Paired $t$-test; ${ }^{*} \mathrm{p}$-value of $<0.05$ was defined as statistically significant. Abbreviations: IOP, intraocular pressure; SD, standard deviation. 


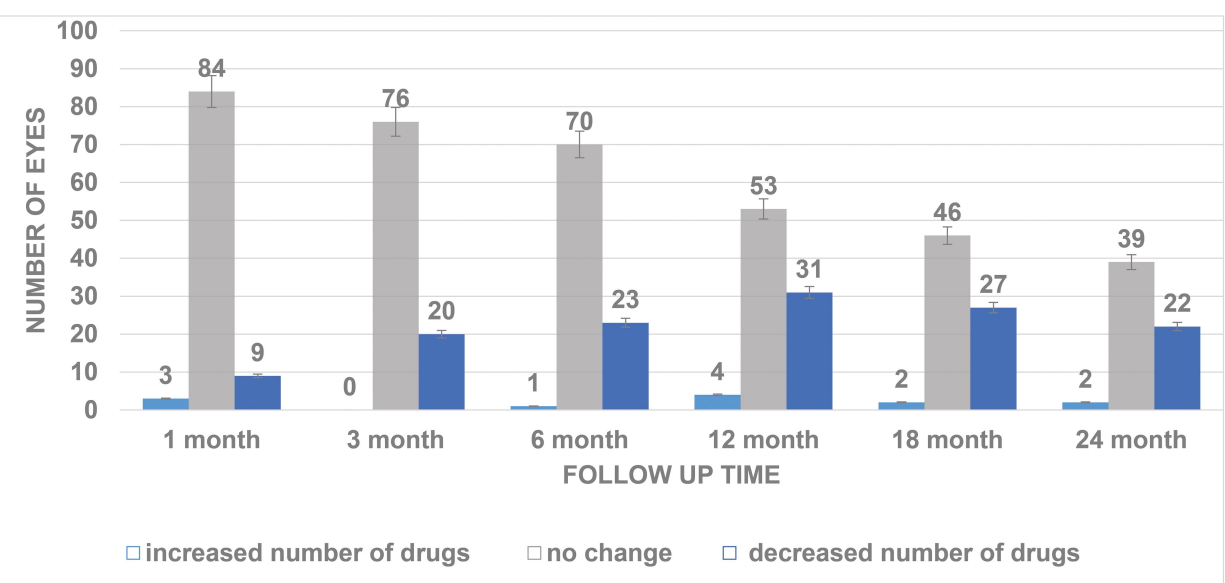

Figure I Anti-glaucoma drugs usage after selective laser trabeculoplasty (SLT) at each follow-up visit. Some eyes had antiglaucoma drug withdrawn since a month after SLT and the number of eyes continued increasing in until last follow-up visit. In the majority of treated eyes, medication regime remained unchanged throughout the follow-up period.

included eyes with NTG whereas number of eyes with PXG was low. All eyes were prescribed antiglaucoma medication before SLT where the mean number of antiglaucoma drugs needed was $2.74 \pm 1.09$. The majority of eyes had moderate to advanced glaucomatous damage and underwent SLT because of uncontrolled IOP with medication $(79.2 \%)$. These data represented the study population with difficulty reducing IOP which might have affected SLT success. Total laser energy was also another possible factor affecting the success rate for which its effect was reported by Lee et al; ${ }^{18}$ we reported mean total laser energy of $56.83 \pm 19.77 \mathrm{~mJ}$.

The action of SLT on the trabecular meshwork (TM) is to increase aqueous outflow, but the mechanism is not well understood. SLT has been demonstrated to induce biological changes, including gene expression, cytokine secretion, matrix metalloproteinase induction and TM remodeling. ${ }^{19}$ Local increases in endothelin- 1 are thought to contribute to acute IOP elevation postSLT ${ }^{20}$ while evidence suggests increased inflammatory response is precipitated after SLT by increased lipid peroxide and decreased antioxidant enzymes. $^{21}$ In our study, more than $10 \%$ postSLT IOP elevation at 1 hour after SLT was a positive predictor of SLT success using both univariate and multivariate analysis. We postulated that transient IOP elevation early after SLT was an indicator representing the ongoing biochemical process of SLT on TM which was further associated with SLT success.

Some studies have reported preSLT IOP was a positive predictor for SLT success ${ }^{6,10,11}$ whereas one study demonstrated the opposite result. ${ }^{25}$ In our study, we found
preSLT IOP was a negative predictor of SLT success using both univariate and multivariate analysis. We postulated that the discrepancy came from different characteristics of the study population. In our study, all eyes were prescribed antiglaucoma medication before SLT, and $86.46 \%$ of eyes needed at least 2 types of antiglaucoma drugs. The majority of eyes underwent SLT because of uncontrolled IOP with medication (79.2\%) Eyes with higher preSLT IOP were likely difficult cases affecting SLT response. Underlying systemic hypertension was found to negatively affect SLT success. This association has never been reported in the literature. We hypothesized that it might not be a direct effect of the disease itself. Antihypertensive drugs may play a major role. There are some studies confirmed the effect of systemic betablockers on IOP. ${ }^{26-28}$ According to Thailand National List of Essential Medicines, systemic beta-blockers are recommended for treating systemic hypertension and internists widely prescribe them. This information was not available in our study. Further study focusing on the effect of various types of antihypertensive drug on SLT success is required.

IOP increased more than $5 \mathrm{mmHg}$ at 1 hour after SLT in 2 eyes $(2.1 \%)$. One eye was defined as SLT success at 1 month follow-up and the effect lasted up to 24 months. The other eye had consistent IOP elevation and needed filtering surgery. The percentage of IOP spikes was lower than that in related studies ${ }^{22,23}$ but comparable with some studies. ${ }^{3,24}$ We hypothesized that it might be a result of different total laser energy or study populations for which De Keyser et al reported using higher laser energy than 
Table 3 Univariate and Multivariate Analysis of the Covariates Affecting Successful SLT Treatment

\begin{tabular}{|c|c|c|c|c|c|c|c|c|}
\hline \multirow{3}{*}{$\begin{array}{l}\text { Covariates } \\
\text { Age }\end{array}$} & \multicolumn{4}{|c|}{ Univariate Analysis } & \multicolumn{4}{|c|}{ Multivariate Analysis } \\
\hline & \multirow{2}{*}{$\begin{array}{c}\begin{array}{c}\text { Crude Odds } \\
\text { Ratio }\end{array} \\
1.001\end{array}$} & \multirow{2}{*}{$\begin{array}{c}\text { p-value } \\
0.411\end{array}$} & \multicolumn{2}{|c|}{$\begin{array}{c}95 \% \\
\text { Confidence } \\
\text { Interval }\end{array}$} & \multirow{2}{*}{$\begin{array}{c}\begin{array}{c}\text { Adjusted Odds } \\
\text { Ratio }\end{array} \\
1.001\end{array}$} & \multirow{2}{*}{$\begin{array}{c}\text { p-value } \\
0.438\end{array}$} & \multicolumn{2}{|c|}{$\begin{array}{c}95 \% \\
\text { Confidence } \\
\text { Interval }\end{array}$} \\
\hline & & & 0.998 & 1.005 & & & 0.999 & 1.002 \\
\hline Sex & $1.07 \mid$ & 0.111 & 0.984 & 1.165 & 1.020 & 0.206 & 0.989 & 1.052 \\
\hline Diabetes mellitus & 0.985 & 0.438 & 0.947 & 1.024 & 0.985 & 0.438 & 0.947 & 1.024 \\
\hline Hypertension & 0.970 & $0.026 *$ & 0.944 & 0.996 & 0.970 & $0.026 *$ & 0.944 & 0.996 \\
\hline Best corrected visual acuity & 1.028 & 0.692 & 0.895 & 1.182 & \multicolumn{4}{|c|}{ Excluded from multivariate logistic analysis } \\
\hline Pre-SLT cup to disc ratio & 1.044 & 0.743 & 0.808 & 1.348 & 0.897 & 0.084 & 0.792 & 1.015 \\
\hline Pre-SLT VFMD & 1.000 & 0.977 & 0.995 & 1.006 & 1.001 & 0.386 & 0.999 & 1.003 \\
\hline Pre-SLT IOP & 0.955 & $<0.001 *$ & 0.945 & 0.966 & 0.991 & $<0.001 *$ & 0.987 & 0.995 \\
\hline \multicolumn{9}{|l|}{ Glaucoma diagnosis } \\
\hline POAG & 1.087 & 0.263 & 0.939 & 1.258 & 0.999 & 0.983 & 0.918 & 1.088 \\
\hline NTG & 0.731 & $0.037^{*}$ & 0.545 & $0.98 \mathrm{I}$ & 0.988 & 0.856 & 0.867 & 1.126 \\
\hline Steroid induced & 0.919 & 0.630 & 0.653 & 1.294 & 0.968 & 0.627 & 0.850 & 1.103 \\
\hline PXG & 1.089 & 0.521 & 0.839 & 1.414 & 1.025 & 0.667 & 0.915 & 1.149 \\
\hline JOAG & 1.028 & 0.817 & 0.812 & 1.302 & 1.167 & $0.007^{*}$ & 1.044 & 1.304 \\
\hline Angle recession & 1.217 & 0.206 & 0.898 & 1.650 & 0.985 & 0.816 & 0.869 & 1.117 \\
\hline Duration of anti-glaucoma drug used & 0.993 & 0.258 & 0.982 & 1.005 & 0.999 & 0.635 & 0.994 & 1.004 \\
\hline Pre-SLT number of anti-glaucoma drugs & 1.008 & 0.142 & 0.997 & 1.019 & \multicolumn{4}{|c|}{ Excluded from multivariate logistic analysis } \\
\hline Pre-SLT beta-blocker used & 1.120 & $0.030^{*}$ & 1.011 & $\mathrm{I} .24 \mathrm{I}$ & 1.003 & 0.901 & 0.961 & 1.046 \\
\hline Pre-SLT alpha2 agonist used & 1.022 & 0.605 & 0.940 & 1.112 & 0.972 & $0.044^{*}$ & 0.945 & 0.999 \\
\hline Pre-SLT prostaglandin analogue used & 0.960 & $0.035^{*}$ & 0.923 & 0.997 & 1.031 & 0.353 & 0.967 & 1.099 \\
\hline Pre-SLT topical CAls used & 0.941 & 0.157 & 0.866 & 1.024 & 1.048 & $0.006 *$ & 1.014 & 1.083 \\
\hline Laser location & 1.105 & $0.040^{*}$ & 1.004 & 1.216 & 1.009 & 0.762 & 0.951 & 1.071 \\
\hline Laser power & 0.767 & 0.164 & 0.528 & 1.115 & \multicolumn{4}{|c|}{ Excluded from multivariate logistic analysis } \\
\hline Total laser energy & 1.000 & 0.556 & 0.998 & $\mathrm{I} .00 \mathrm{I}$ & 1.000 & 0.556 & 0.998 & 1.001 \\
\hline IOP elevation $>10 \%$ at I hour & 1.042 & $0.037^{*}$ & 1.002 & 1.083 & 1.040 & $0.046^{*}$ & 1.001 & 1.081 \\
\hline \multicolumn{9}{|l|}{ Post laser medication } \\
\hline Steroid & 0.962 & 0.704 & 0.789 & 1.173 & 1.015 & 0.678 & 0.945 & 1.090 \\
\hline NSAIDs & 0.850 & $0.001 *$ & 0.775 & 0.933 & 0.985 & 0.446 & 0.946 & 1.025 \\
\hline
\end{tabular}

Note: *p-value of $<0.05$ was defined as statistically significant.

Abbreviations: GEE, generalized estimating equations; SLT, selective laser trabeculoplasty; VFMD, visual field mean deviation; IOP, intraocular pressure; POAG, primary open-angle glaucoma; NTG, normal tension glaucoma; PXG, pseudoexfoliation glaucoma; JOAG, juvenile open-angle glaucoma; CAls, carbonic anhydrase inhibitors; NSAIDs, non-steroidal anti-inflammatory drugs.

ours while a study by Lai et al focused on newly diagnosed POAG subjects without prior treatment. One eye experienced hypotony; IOP of $5 \mathrm{mmHg}$, with neither related complication nor significant inflammation at 1 week after SLT. This patient was diagnosed with POAG which was adequately controlled with three antiglaucoma drugs. He received SLT due to drug intolerance. No history of uveitis was observed. The laser power of $0.7 \mathrm{~mJ}$ was applied for totally 94 spots. All antiglaucoma drugs were stopped and IOP returned to normal range shortly. 
IOP was higher, therefore two antiglaucoma drugs were prescribed at 2 months after SLT. Favorable IOP was achieved through study period. This was the first case of reported hypotony after SLT.

SLT began to be ineffective after 12 months. In all, $3.4 \%, 8.0 \%$ and $4.8 \%$ of eyes needed additional laser or surgery at 12, 18 and 24 months, respectively. Most eyes $(83.8 \%)$ maintained favorable IOP up to 24 months with medical treatment which was comparable with the qualified success rate reported by Lee et al. ${ }^{6}$

This study had some limitations due to retrospective study design which was unavoidable of bias. Some preSLT ocular parameters which may have affected study outcome were not recorded such as angle pigmentation, anterior chamber depth and refraction. SLT was performed by various glaucoma specialists and laser energy used depended on doctor preference. Follow-up visits started from one month after SLT, so the possibility existed of missing some complications during that period. Antiglaucoma medication regime modification could occur anytime depending on indication of SLT and doctor's decision which affected IOP outcome.

\section{Conclusions}

SLT had a favorable outcome in treating open-angle glaucoma in a Thai population. IOP significantly decreased as well as the number of antiglaucoma drugs needed after SLT. Efficacy of SLT lasted up to 24 months in most cases. More than 10\% postSLT IOP elevation at 1 hour was a positive predictor of SLT success. On the contrary, systemic hypertension and preSLT IOP were negative predictors of SLT success.

\section{Acknowledgment}

Supak Caengow.

Research assistant. Phramongkutklao College of Medicine, Bangkok, Thailand 10400.

\section{Disclosure}

The authors report no conflicts of interest for this work.

\section{References}

1. Kadasi LM, Wagdi S, Miller KV. Selective laser trabeculoplasty as primary treatment for open-angle glaucoma. $R$ I Med $J$ (2013). 2016;99:22-25.

2. Leahy KE, White AJ. Selective laser trabeculoplasty: current perspectives. Clin Ophthalmol. 2015;9:833-841. doi:10.2147/OPTH. S53490
3. Bovell AM, Damji KF, Hodge WG, Rock WJ, Buhrmann RR, Pan YI. Long term effects on the lowering of intraocular pressure: selective laser or argon laser trabeculoplasty? Can J Ophthalmol. 2011;46:408-413. doi:10.1016/j.jcjo.2011.07.016

4. Schlote T, Kynigopoulos M. Selective laser trabeculoplasty (SLT): 1-year results in early and advanced open angle glaucoma. Int Ophthalmol. 2016;36:55-61. doi:10.1007/s10792-015-0079-1

5. Miraftabi A, Nilforushan N, Nassiri N, Nouri-Mahdavi K. Selective laser trabeculoplasty in patients with pseudoexfoliative glaucoma vs primary open angle glaucoma: a one-year comparative study. Int J Ophthalmol. 2016;9:406-410. doi:10.18240/ijo.2016.03.14

6. Song J, Lee PP, Epstein DL, et al. High failure rate associated with 180 degrees selective laser trabeculoplasty. $J$ Glaucoma. 2005;14:400-408. doi:10.1097/01.ijg.0000176939.43681.c2

7. Lee JW, Ho WL, Chan JC, Lai JS. Efficacy of selective laser trabeculoplasty for normal tension glaucoma: 1 year results. $B M C$ Ophthalmol. 2015;15:1. doi:10.1186/1471-2415-15-1

8. Lee JW, Shum JJ, Chan JC, Lai JS. Two-year clinical results after selective laser trabeculoplasty for normal tension glaucoma. Medicine (Baltimore). 2015;94:e984. doi:10.1097/MD.0000000000000984

9. Maleki A, Swan RT, Lasave AF, Ma L, Foster CS. Selective laser trabeculoplasty in controlled uveitis with steroid-induced glaucoma. Ophthalmology. 2016;123:2630-2632. doi:10.1016/j. ophtha.2016.07.027

10. Martow E, Hutnik CM, Mao A. SLT and adjunctive medical therapy: a prediction rule analysis. $J$ Glaucoma. 2011;20:266-270. doi:10.1097/IJG.0b013e3181e3d2c1

11. Kim YJ, Moon CS. One-year follow-up of laser trabeculoplasty using Q-switched frequency-doubled Nd: YAG laser of $523 \mathrm{~nm}$ wavelength. Ophthalmic Surg Lasers. 2000;31:394-399.

12. Lee JW, Lai JS. A review of selective laser trabeculoplasty in the Hong Kong Chinese population. Hong Kong Med J. 2016;22:165-170. doi:10.12809/hkmj154641

13. Melamed S, Ben Simon GJ, Levkovitch-Verbin H. Selective laser trabeculoplasty as primary treatment for open-angle glaucoma: a prospective, nonrandomized pilot study. Arch Ophthalmol. 2003;121:957-960. doi:10.1001/archopht.121.7.957

14. Barkana Y, Belkin M. Selective laser trabeculoplasty. Surv Ophthalmol. 2007;52:634-654. doi:10.1016/j. survophthal.2007.08.014

15. Lee JW, Liu CC, Chan JC, Lai JS. Predictors of success in selective laser trabeculoplasty for Chinese open-angle glaucoma. $J$ Glaucoma. 2014;23:321-325. doi:10.1097/IJG.0000000000000049

16. Song J. Complications of selective laser trabeculoplasty: a review. Clin Ophthalmol. 2016;10:137-143. doi:10.2147/OPTH.S84996

17. Polat J, Grantham L, Mitchell K, Realini T. Repeatability of selective laser trabeculoplasty. $B r \quad J$ Ophthalmol. 2016;100:1437-1441. doi:10.1136/bjophthalmol-2015-307486

18. Lee JW, Wong MO, Liu CC, Lai JS. Optimal selective laser trabeculoplasty energy for maximal intraocular pressure reduction in open-angle glaucoma. J Glaucoma. 2015;24:e128-31. doi:10.1097/ IJG.0000000000000215

19. Kagan DB, Gorfinkel NS, Hutnik CM. Mechanisms of selective laser trabeculoplasty: a review. Clin Exp Ophthalmol. 2014;42:675-681. doi:10.1111/ceo.12281

20. Guzey M, Vural H, Satici A. Endothelin-1 increase in aqueous humour caused by frequency-doubled Nd: YAG laser trabeculoplasty in rabbits. Eye (Lond). 2001;15:781-785. doi:10.1038/eye.2001.249

21. Guzey M, Vural H, Satici A, Karadede S, Dogan Z. Increase of free oxygen radicals in aqueous humour induced by selective Nd: YAG laser trabeculoplasty in the rabbit. Eur J Ophthalmol. 2001;11:47-52. doi:10.1177/112067210101100109

22. Lai JS, Chua JK, Tham CC, Lam DS. Five-year follow up of selective laser trabeculoplasty in Chinese eyes. Clin Exp Ophthalmol. 2004;32:368-372. doi:10.1111/j.1442-9071.2004.00839.x 
23. De Keyser M, De Belder M, De Groot V. Randomized prospective study of the use of anti-inflammatory drops after selective laser trabeculoplasty. $J$ Glaucoma. 2017;26:e22-9. doi:10.1097/ IJG.0000000000000522

24. Narayanaswamy A, Leung CK, Istiantoro DV, et al. Efficacy of selective laser trabeculoplasty in primary angle-closure glaucoma: a randomized clinical trial. JAMA Ophthalmol. 2015;133:206-212. doi:10.1001/jamaophthalmol.2014.4893

25. Miki A, Kawashima R, Usui S, Matsushita K, Nishida K. Treatment outcomes and prognostic factors of selective laser trabeculoplasty for open-angle glaucoma receiving maximal-tolerable medical therapy. J Glaucoma. 2016;25:785-789. doi:10.1097/IJG.0000000000000411

26. Khawaja AP, Chan MP, Broadway DC, et al. Systemic medication and intraocular pressure in a British population: the EPIC-Norfolk Eye Study. Ophthalmology. 2014;121:1501-1507. doi:10.1016/j. ophtha.2014.02.009
27. Ho H, Shi Y, Chua J, et al. Association of systemic medication use with intraocular pressure in a multiethnic Asian population: the Singapore epidemiology of eye diseases study. JAMA Ophthalmol. 2017;135:196-202. doi:10.1001/jamaophthalmol.2016.5318

28. Höhn R, Mirshahi A, Nickels S, et al. Cardiovascular medication and intraocular pressure: results from the Gutenberg Health Study. $\mathrm{Br}$ J Ophthalmol. 2017;101:1633-1637. doi:10.1136/bjophthalmol2016-309993
Clinical Ophthalmology

\section{Publish your work in this journal}

Clinical Ophthalmology is an international, peer-reviewed journal covering all subspecialties within ophthalmology. Key topics include: Optometry; Visual science; Pharmacology and drug therapy in eye diseases; Basic Sciences; Primary and Secondary eye care; Patient Safety and Quality of Care Improvements. This journal is indexed on PubMed

Submit your manuscript here: https://www.dovepress.com/clinical-ophthalmology-journal
Dovepress

Central and CAS, and is the official journal of The Society of Clinical Ophthalmology (SCO). The manuscript management system is completely online and includes a very quick and fair peer-review system, which is all easy to use. Visit http://www.dovepress.com/ testimonials.php to read real quotes from published authors. 